\title{
New trends in improving gasoline quality and octane through naphtha isomerization: a short review
}

\author{
Salman Raza Naqvi ${ }^{1}$ (1) Ayesha Bibi ${ }^{1} \cdot$ Muhammad Naqvi $^{2} \cdot$ Tayyaba Noor $^{1} \cdot$ Abdul-Sattar Nizami $^{3}$. \\ Mohammad Rehan ${ }^{3} \cdot$ Muhammad Ayoub $^{4}$
}

Received: 8 October 2017 / Accepted: 18 June 2018 / Published online: 27 June 2018

(c) The Author(s) 2018

\begin{abstract}
The octane enhancement of light straight run naphtha is one of the significant solid acid catalyzed processes in the modern oil refineries due to limitations of benzene, aromatics, and olefin content in gasoline. This paper aims to examine the role of various catalysts that are being utilized for the isomerization of light naphtha with an ambition to give an insight into the reaction mechanism at the active catalyst sites, and the effect of various contaminants on catalyst activity. In addition, different technologies used for isomerization process are evaluated and compared by different process parameters.
\end{abstract}

Keywords Catalyst · Isomerization · Light naphtha $\cdot$ Octane number · Oil refineries

\section{Introduction}

Today, there is a consensus to enhance fuels quality to reduce their detrimental impacts on the environment and human health [1]. As a result, restrictions are imposed on gasoline to reduce its benzene, cyclic compounds, heavy aromatics, and olefin concentrations along with the removal of tetramethyl lead [2]. However, the octane number of aromatics and olefins is relatively high, so reducing their concentration in gasoline causes a decrease in octane number and, consequently, fuel quality $[3,4]$. Therefore, the process of isomerization is gaining significant attention in the petroleum refineries to increase the fuel octane number [5]. However, the process mainly depends on the catalysts and how efficient they are in their activity and selectivity [2].

Salman Raza Naqvi

salman.raza@scme.nust.edu.pk

1 School of Chemical and Materials Engineering, National University of Sciences and Technology, H-12, Islamabad, Pakistan

2 Department of Energy, Building and Environment, Future Energy Center, Mälardalen University, Västerås, Sweden

3 Centre of Excellence in Environmental Studies (CEES), King Abdulaziz University, Jidda, Saudi Arabia

4 Department of Chemical Engineering, Universiti Teknologi PETRONAS, 32610 Bandar Seri Iskandar, Perak, Malaysia
The heterogeneous catalysts are used more than homogeneous catalysts due to their high reactivity during the process and ease of catalyst separation [5]. The reusability of catalysts is critical from financial and environmental prospects [6]. Moreover, the different types of reactions and their mechanisms taking place at the active reaction sites of the catalysts are the key factors in the isomerization process. Therefore, to achieve the required yield and conversion of $n$-paraffin, the catalyst should have a suitable shape and compositional characteristics, especially correct ratios of metal and acid [7].

The process of light naphtha isomerization mainly bases on the chlorinated platinum promoted alumina catalysts [3]. These active catalysts function even at a low temperature, which is a favorable condition for the process of isomerization. In earlier times, aluminum chloride was used as a catalyst in isomerization to produce iso-butane [4]. Afterward, many other catalysts have been developed but operated at a high temperature with reduced conversion of naphtha due to their lower activity. Therefore, highly active dual function catalysts are developed in recent years that can be operated at a lower temperature with high conversion of naphtha [6]. The types of catalysts used for the isomerization process of light naphtha are mixed metal oxide- and zeolite-based catalysts [2].

The suitability of catalyst type depends on the isomerization process temperature. For example, the Pt-chlorinated alumina is the most active catalyst for isomerization, 
and they are operated at lower temperatures $\left(20-130^{\circ} \mathrm{C}\right)$. The mixed metal oxide catalysts are less reactive than Ptchlorinated alumina base catalyst, so they are operated at a relatively higher temperature (around $150{ }^{\circ} \mathrm{C}$ ) [6-8]. The chlorinated alumina catalysts produce compounds with higher octane number. However, the chlorinated Pt/ $\mathrm{Al}_{2} \mathrm{O}_{3}$ catalyst requires a promoter to enhance its activity [10]. These catalysts are highly susceptible to contamination during their use and can lead to catalyst poisoning. Therefore, the feedstock is required to be preheated to obtain the required products $[1,8,9]$. Several studies have been carried out with varying amount of different metal content in the catalyst and the experimental results showed that Ni-Pt mixed metal oxide $(0.2 \% \mathrm{Pt}$ and $0.4 \%$ $\mathrm{Ni}$ ) showed lesser activity and yield of $n$-paraffin than $\mathrm{Pd}-\mathrm{Pt}(0.2 \% \mathrm{Pt}$ and $0.4 \% \mathrm{Pd})$ mixed metal oxide catalyst [8-10].

The isomerization process has low capital cost and produces a more valuable product with optimum specifications such as research octane number (RON) and aromatics concentrations than other methods [2]. Whereas reforming produces more aromatic compounds and less isoparaffin than isomerization [5]. The product produced by isomerization has a small difference between RON and motor octane number (MON) [8]. The increasing worldwide significance of isomerization in oil refineries encourages the researchers to conduct detailed reviews on this topic. This study, therefore, aims to examine the role of various catalysts in the isomerization of light naphtha. A special focus is given to the reaction mechanism at the active catalyst sites, and the effect of different contaminants on catalyst activity. Furthermore, the current process challenges and possibilities of process optimization are also discussed.

\section{Key factors influencing the isomerization process}

\section{Feed to isomerization unit and its characteristics}

Light straight run naphtha (LSRN) is rich in $n$-pentane and $n$-hexane. Other feedstock to the isomerization process may come from thermal processes like visbreaking, delayed coking, fluid catalytic cracking (FFC) of naphtha, light reformate, light hydrocracked naphtha and from condensate naphtha. The feedstock also contains some fractions of benzene, olefins, and heavy hydrocarbon compounds $\left(\mathrm{C}^{7+}\right)$. Therefore, the feedstock is characterized by $\mathrm{X}$-factor that determines the number of heavy hydrocarbons, mainly $\mathrm{C}_{6}$ cyclic and $\mathrm{C}_{7}^{+}$compounds, present in the feedstock. Feedstock with a high value of $\mathrm{X}$-factor will have a lower value of octane number of the product. X-factor is estimated using the following equation:

$$
\begin{aligned}
\mathrm{X} \text {-factor }= & (\text { wt. } \% \text { Methylcyclopentane })+(\text { wt. \% Benzene }) \\
& +(\text { wt. } \% \text { cyclohexane })+\left(\text { wt. } \% C_{7}^{+}\right)
\end{aligned}
$$

\section{Key isomerization reactions and their conditions}

The key reactions taking place in the isomerization unit is listed in Table 1. Isomerization is a limited equilibrium and exothermic reaction [9]. According to Le Chatelier's principle, such reactions are favorable at low temperatures. The complete conversion of $n$-paraffin to iso-paraffin is not possible due to equilibrium limitations [11]. The heat of reaction for isomerization, $\mathrm{C}_{7}{ }^{+}$hydrocracking, naphthene ring opening, and benzene saturation are 2200, 11,000, 11,000 and $50,000 \mathrm{kcal} / \mathrm{kg}-\mathrm{mol}$, respectively. These values show that benzene saturation is a highly exothermic reaction and reduces the yield of the isomerates. Therefore, there should be a limited fraction of benzene in the feedstock [11-13].

Table 1 Important reactions take place in isomerization unit and their features

\begin{tabular}{lll}
\hline Major reactions & Reactions & Features \\
\hline Isomerization & $n-\mathrm{C}_{5} \mathrm{H}_{12} \rightarrow \mathrm{i}-\mathrm{C}_{5} \mathrm{H}_{12}$ & It is a desirable reaction in the isomerization process \\
$n-\mathrm{C}_{6} \mathrm{H}_{14} \rightarrow 2$-methylpentane & It is favorable at low temperature and high pressure [35] \\
$n-\mathrm{C}_{6} \mathrm{H}_{14} \rightarrow 3-$-methylpentane & It enhances the octane number of the product \\
$2-$-methylpentane $\rightarrow 2.3$ dimethyl butane & It is exothermic in nature \\
& $\mathrm{C}_{6} \mathrm{H}_{6}+3 \mathrm{H}_{2} \rightarrow \mathrm{CH}$ & It takes place at both acidic and metallic site of the catalyst \\
& & It is a desirable reaction
\end{tabular}


Table 1 shows the various reactions taking place in the isomerization reactors. Benzene saturation is the fastest reaction that takes place at the active metal site of the catalyst and top of the reactor. The heat energy released by the reaction is approximately 50 times greater than the heat energy released by the isomerization. The isomerization reaction takes place at both metallic and acidic sites. The reaction starts at the metallic site and then continues at the acidic site and follows the mechanism in which firstly there is dehydrogenation of alkane at the metallic site, and alkene will form. Afterward, there will be a rearrangement of alkene on the acidic site, and $n$-alkene is converted to iso-alkene. Finally, it will be followed by the hydrogenation of alkene to form iso-alkane. The other reactions that take place are the hydrocracking and naphthene ring opening reactions, which are also exothermic reactions. The naphthene ring opening is one of the favorable reactions, because if naphthene does not convert to an alkane, it will block the acidic site and hinder the isomerization reactions and reduce the activity of the catalyst $[12,13]$. Figure 1 shows the mechanism for the conversion of $n$-alkane to iso-alkane over a bi-functional metal promoted solid-acid catalyst [14]. The performance of the isomerization unit is estimated through its iso ratio and paraffin isomerization number (PIN) parameters using following equations 2 and 3 .

For butane isomerization unit, the iso ratio is defined as

Iso butane ratio $=\left(i \mathrm{C}_{4}\right) /\left(n \mathrm{C}_{4}+i \mathrm{C}_{4}\right)$.
For LSRN, the iso ration is defined as

$\mathrm{iC}_{5} / \mathrm{C}_{5} \mathrm{P}=\mathrm{iC}_{5} /\left(\mathrm{iC} 5+n \mathrm{C}_{5}\right)$.

\section{Process variables for isomerization}

The critical process parameters for the isomerization of the LSRN are temperature, pressure, liquid hourly space velocity (LHSV), feedstock composition, $\mathrm{H}_{2}$ /hydrocarbon ratio and catalyst promoter [1]. The temperature of the process should be kept low as isomerization is an exothermic reaction and rate of isomerate formation will increase the temperature of the process, but it should not be kept too low that the activity of the catalyst would decrease to a greater extent [2-4]. There should be an optimum value of pressure that is $45 \mathrm{psig}$. Although increasing the pressure does not affect the isomerate product ratio, but it increases the operating cost. The pressure below the optimum value will affect the activity of the catalyst as the $\mathrm{C}_{6}$ cyclic compounds will block the active sales.

The LHSV has an inverse relation with the isomerate ratio, as it can be seen in Eq. 4. As the LHSV increases, the feedstock does not have enough time to contact with the catalyst to produce iso-paraffin. LHSV is defined as follows:

LHSV $\left(\mathrm{h}^{-1}\right)=$ Reactor feed flowrate $\left(\mathrm{ft}^{3} / \mathrm{h}\right.$. $) /$ catalyst volume $\left(\mathrm{ft}^{3}\right)$.

The design value is between 1 and 2 .

Fig. 1 Reaction mechanism of hydroisomerization of $n$-alkane [14]

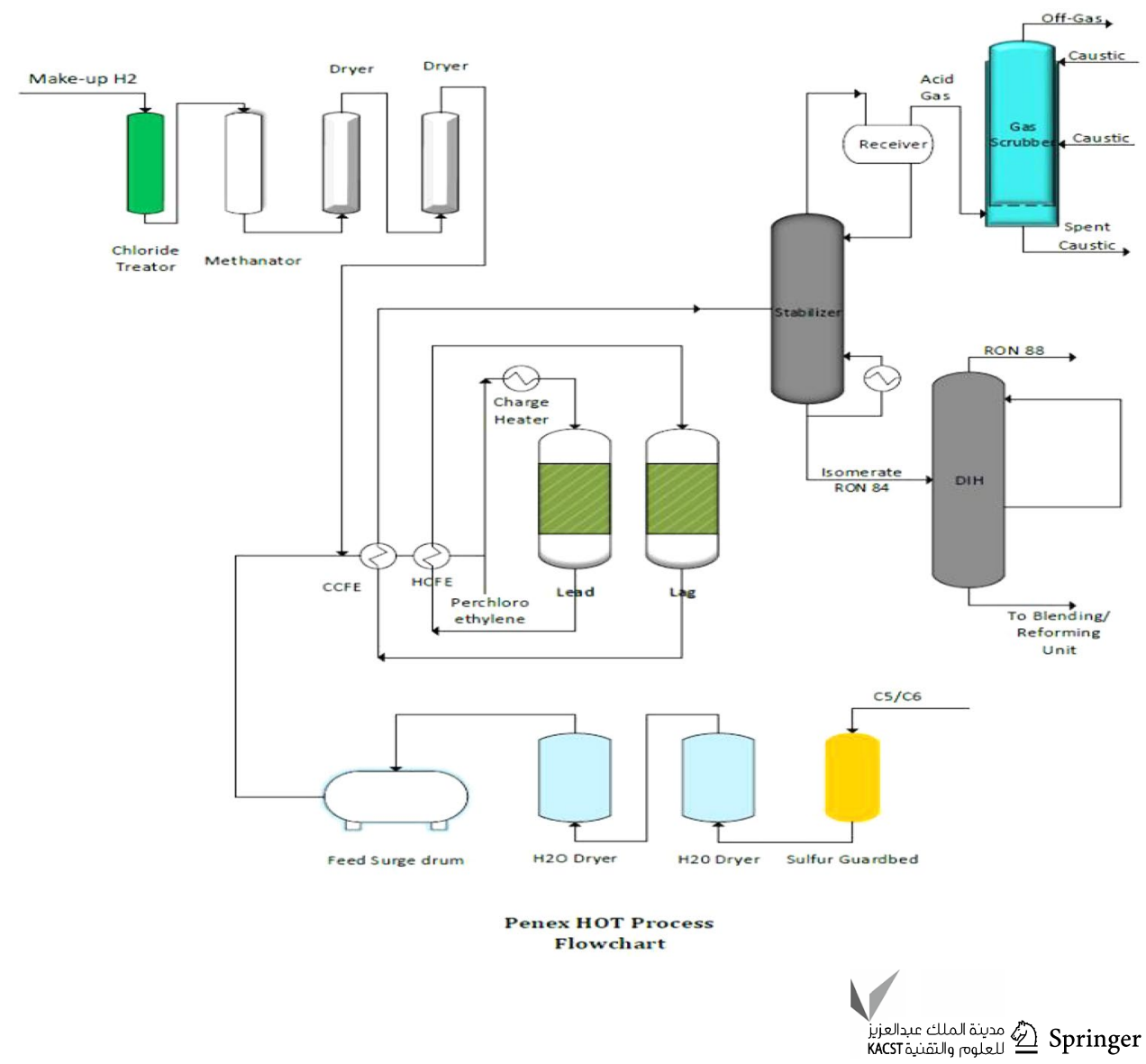


Feed should contain a lesser amount of benzene, as benzene saturation reaction takes place in isomerization, which is a highly exothermic reaction that reduces the production of isomerate. The $\mathrm{H}_{2}$ /hydrocarbon ratio is also one of the important factors to be considered. The following equations 5 and 6 can be used to calculate the $\mathrm{H}_{2}$ /hydrocarbon ratios.

The hydrogen to hydrocarbon ratio for recycling gas process is defined as

The hydrogen to hydrocarbon ratio for once-through process is defined as

The hydrogen to hydrocarbon ratio for once-through the process has a typical value of 0.05 , and the hydrogen to hydrocarbon ratio for the recycling gas process has a typical value between 1 and 2 . This ratio ensures that excess hydrogen is available throughout the process $[1,15]$.

\section{Classification of isomerization}

\section{Classification of isomerization process by feedstock}

There are three types of isomerization processes based on feedstock. The first one is the $\mathrm{C}_{5} / \mathrm{C}_{6}$ isomerization, where the reactions mainly take place in the liquid phase. The aim is to convert $n$-paraffin to iso-paraffin using a catalyst and hence increase the quality of gasoline. The $\mathrm{nC}_{6}$ is isomerized to produce the mono and di-substituted paraffin, which has higher octane number than the n-paraffin. The second is the isomerization of $n$-butane to iso-butane, which has a wide range of applications in the methyl tertiary butyl ether (MTBE) production. In addition, it is used in alkylation process and butyl rubber production. The feedstock in this type is in the vapor phase. The third is the isomerization of $\mathrm{C}_{7}{ }^{+}$ hydrocarbons. It is used because of the limitations of heavy fraction and $\mathrm{C}_{7}{ }^{+}$hydrocarbons and to get the high-octane product. Initially, the $\mathrm{C}_{7}{ }^{+}$hydrocarbons are converted to mono-substituted hydrocarbons, and then into di-substituted hydrocarbons. The rate constant for the conversion of monosubstituted feed to di-substituted is quite low. Moreover, it enhances the chances of hydrocracking, due to the increase in molecular weight.

\section{Classification of isomerization process by catalyst}

Isomerization is classified into five categories based on catalyst, where isomerization of LSRN, butane, and $\mathrm{C}_{7}^{+}$compounds are carried out in the presence of different types of catalysts [8]. The three types of catalysts used in the $\mathrm{H}_{2} /$ hydrocarbon $=$ moles of hydrogen in recycle gas $/$ moles of hydrocarbon in feed stream.

$\mathrm{H}_{2} /$ hydrocarbon $=$ moles of hydrogen in stabilizer off gases $/$ moles of hydrocarbon in feed stream.

isomerization of LSRN are platinum chlorinated (alumina base), zeolites, metal oxide base (zirconia based). Whereas the catalyst used for the isomerization of $n$-butane is a sulfated oxide, and H-ZSM 5 is used for the isomerization of $\mathrm{C}_{7}^{+}$hydrocarbons [16]. The process variables for different catalyst are listed in Table 2 . The process temperature varies during the isomerization process of LSRN with the type of catalyst used (Table 2). Normally the required process temperature, is in order of lowest to highest for alumina, zirconia based (mixed metal oxide) and zeolites catalysts, respectively, for optimum isomerate products $[17,18]$.

The catalysts used for the isomerization process are dual functional. They contain an acidic and a metallic site. Table 3 shows the different reactions taking place in isomerization (catalyst functionality) and the preferred catalytic sites in which various reactions take place. For instance, chlorinated alumina has high activity than zeolites based catalysts so they can be operated at lower temperatures. Whereas zeolites operate at higher temperatures, so they have lower octane boost [13]. Chlorinated alumina has very lower tolerance to contaminants like oxygenates, sulfur, nitrogen, and fluorine, so feedstock requires pretreatment and a small amount of promoter that can be an organic chloride to meet the activity of the catalyst [18]. The sulfate catalyst has emerged as a promising catalyst in recent years that can bear contaminants like sulfur and water. Zeolites

Table 2 Process variables for different isomerization catalyst

\begin{tabular}{llllll}
\hline Process variables & Pt-chlorinated alumina & $\begin{array}{l}\text { Metal oxides (zir- } \\
\text { conia based) }\end{array}$ & Zeolites & Sulfated oxide & H-ZSM 5 \\
\hline Feed stock & $\mathrm{C}_{5} / \mathrm{C}_{6}$ & $\mathrm{C}_{5} / \mathrm{C}_{6}$ & $\mathrm{C}_{5} / \mathrm{C}_{6}$ & $n$-butane & $\mathrm{C}^{7}+$ hydrocarbons \\
Pressure (bar g) & $20-30[37]$ & $15-35$ & $15-30[37]$ & No less than $15[38]$ & $10-20[39]$ \\
LHSV $\left(\mathrm{h}^{-1}\right)$ & $1.0-2.0[37]$ & $1.0-3.0$ & $1.0-2.0[37]$ & $6-10[38]$ & $1.5-2.0[39]$ \\
Temperature $\left({ }^{\circ} \mathrm{C}\right)$ & $120-180[37]$ & $180-210$ & $250-270[37]$ & $180-200[38]$ & $160-200[39]$ \\
$\mathrm{H}_{2} /$ hydrocarbon ratio & $0.1-2.0[37]$ & $1.0-2.0$ & $2.0-4.0[37]$ & $0.06-0.1[38]$ & $1.0-2.0[39]$ \\
\hline
\end{tabular}


Table 3 Catalyst functionality

\begin{tabular}{ll}
\hline Reactions & Catalyst site \\
\hline Paraffin isomerization & Metal/acidic \\
Benzene saturation & Metal \\
Naphthene isomerization & Acidic \\
Naphthene ring opening & Metal \\
Hydrocracking & Acidic \\
Heavies formation & Metal \\
\hline
\end{tabular}

Table 4 Feed impurities tolerances of different isomerization catalysts

\begin{tabular}{llll}
\hline Feedstock conditions & $\begin{array}{l}\text { Chlorinated } \\
\text { alumina }\end{array}$ & Zeolite & Metal oxide \\
\hline Sulphur $(\mathrm{ppm})$ & None & $<200$ & $<20$ \\
Water $(\mathrm{ppm})$ & None & $<200$ & $<20$ \\
Benzene $\%$ & $<2$ & $<10$ & $<2$ \\
$\mathrm{C}_{7}{ }^{+} \%$ & $<2$ & $<5$ & $<2$ \\
\hline
\end{tabular}

are crystalline silico-aluminates that provide an acidic site to the catalyst. Platinum is impregnated to zeolites surface. Moreover, the zeolites have tolerance for the impurities, so feedstock pretreatment is not required. However, due to their lower activity, they are operated at a higher temperature [19]. Ferrierite (FER) zeolite catalyst has noticeable pore size and acidity, thus involved in various catalytic reactions such as isomerization of butenes [2,20].

Table 4 shows the maximum tolerances of contaminants like sulfur, water, $\mathrm{C}_{7}{ }^{+}$, and benzene bearing on the catalyst [8]. Deactivation of the catalyst is the loss of catalytic activity and selectivity with the passage of time due to contaminants and impurities. It is one of the primary problems in the oil refineries which leads to poor performance of the reactor. The oil industries have to bear huge cost of billions of dollars every year for catalyst replacement and process shutdown [21]. Deactivation of the catalyst with time is unavoidable in most of the processes, though regeneration of catalyst slows down the deactivation. There is a significant attention to comprehend decay and regeneration of the catalyst. Therefore, the science and understanding of deactivation and regeneration of the catalyst are emerging rapidly. The catalyst deactivation is caused due to chemical, thermal and mechanical processes such as poisoning, fouling, thermal degradation, vapor formation, by vapor-solid and solid-solid reactions. The recent research and development in deactivation and regeneration of catalyst comprises of (1) essential and practical studies of deactivation and regeneration of catalyst at different scales to comprehend the process chemistry (2) study of the reaction kinetics, and (3) advancements in models for the deactivation and regeneration of catalyst $[22,23]$.
Table 4 shows the maximum tolerable limit of various contaminants in the feedstock stream. The zeolite-based catalysts have maximum tolerance for the impurities, and chlorinated alumina has the minimum tolerance for the impurities [24]. Whereas mixed metal oxide catalysts lie in between both of them and have intermediate characteristics of both the zeolite and chlorinated alumina catalyst. However, they have less yield than chlorinated alumina catalysts due to their higher operating temperature [25].

Recently, two new catalysts, $\mathrm{Pt} / \mathrm{HX}$, and $\mathrm{Pt} / \mathrm{SrX}$ have been developed that showed high resistance to contamination and water and can increase the octane number more than chlorinated alumina and zeolites catalysts [26]. The results showed that $90 \%$ of the carbon atoms present in the feedstock was detected in the final product, whereas rest of the $10 \%$ were lost due to carbon deposition that leads to catalyst deactivation. In another study. The effect of temperature on the conversion of $n$-hexane and $n$-pentane was examined using $\mathrm{Pt} / \mathrm{Al}$ catalyst in a continuous fixed bed reactor at atmospheric pressure. The results show that the yield of iso hexane increases with the increase in temperature up to $400{ }^{\circ} \mathrm{C}$. Afterward, the yield of the isomers decreases when the temperature increases above $400^{\circ} \mathrm{C}$, but the yield of cyclization and cracking products keep on increasing with the increase in temperature [27]. The ratio of benzene/methyl cyclo pentane increases with increase in temperature, which shows that the rate of benzene formation is more than methyl cyclo pentane (MCP). Whereas the ratio of $2 \mathrm{MP} / 3 \mathrm{MP}$ was constant throughout the reaction, which means there are equal chances for the production of both the isomers under the reaction conditions. The effect of chloride ion on the isomerate was also examined, and results show that with the addition of small amount of chloride, significant changes in the isomerate occurs with the increase in the rate of isomerization reaction [27].

\section{Classification of isomerization process by configuration}

There are two primary classifications of isomerization based on the configuration. These are once-through and recycling process. In the once-through process, there is no recycle of hydrogen, methyl pentanes and unreacted feed back to the reactor feed stream and the octane number of achieved is between 78 and 82 . On the other hand, in recycling process, there is the recycle of methyl pentanes and unreacted feed back to the reactor feed stream, which increases the octane number of products up to 88-92.

In once-through process, feed is mixed with the makeup hydrogen gas after passing through the heat exchanger and then enters the first reactor, where isomerization and benzene saturation reactions occur. The mixture then passes through the heat exchanger to lower its temperature,

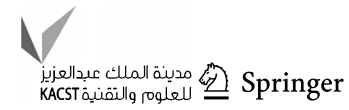


which increases due to benzene saturation, and enters the second reactor, where isomerization reaction takes place. The effluent lag reactor is then sent to the stabilizer to remove lighter fractions. Figure 2 shows the configuration of the once-through process $[28,29]$. In the recycling process, the most important scheme used is DIH (Deisohexanizer), which converts $n$-paraffin to iso-paraffin. The lower octane number methyl pentanes are recycled back to the reactor to be converted into more branched and higher octane number compounds. Another scheme that is used is MOLEX (Molecular sieve adsorption), which separates iso-paraffin and $n$-paraffin by the size of molecular sieve and recycles the methyl pentane back to the reactor. Figures 3 and 4 show the configuration of industrial isomerization processes with recycling [30].

\section{Commercial isomerization processes}

Isomerization, due to its enormous applications, has been used commercially for the production of high-quality gasoline. Many companies are using the isomerization
Fig. 2 Flow sheet of industrial isomerization process $[28,29]$

Fig. 3 Flow sheet of industrial IPSORB ${ }^{\mathrm{TM}}$ process

Fig. 4 Flow sheet of industrial HEXORB $^{\mathrm{TM}}$ process
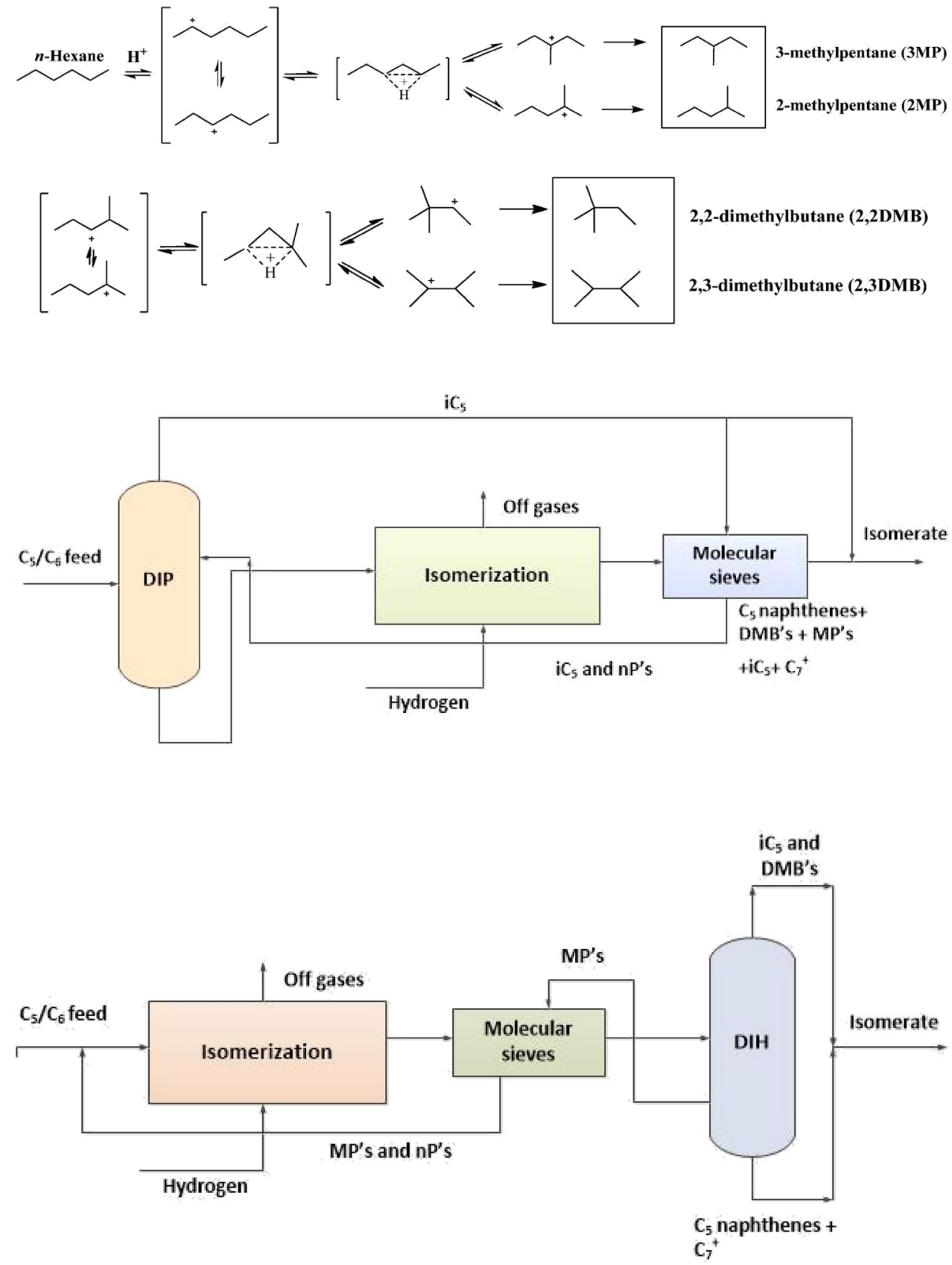
technology commercially, including GTC, Axen and UOP isomerization processes that are discussed below.

\section{GTC isomerization technology}

GTC technology uses various processes for the isomerization of $n$-butane, LSR, and $\mathrm{C}_{7}{ }^{+}$hydrocarbons. Isomalk- $3^{\mathrm{SM}}$ is the process used for the isomerization of $n$-butane to isobutane [30]. It uses a low-temperature isomerization process, and only non-chlorinated technology is being used for $n$-butane. Iso-butane is a vital intermediate product that is essential for the manufacturing of isobutylene or alkylate. Isobutylene is further used for the production of MTBE or important petrochemicals. The isomalk-3sm process use mixed metal oxide catalyst that is very selective towards the formation of i-butane and operates at a temperature range of around $150-170{ }^{\circ} \mathrm{C}$ [31]. The predictable period of the SI-3 catalyst is about 10 years. The process reduces the requirement for chlorine injection. Contaminants like water, sulfur, and nitrogen for the feedstock are lowered [30, 31].

Isomalk- $4^{\mathrm{SM}}$ is the process used for the isomerization of $\mathrm{C}_{7}{ }^{+}$hydrocarbons. In the process, a robust platinumcontaining mixed metal oxide SI- 2 catalyst works effectively at lower temperature range of around $120-140^{\circ} \mathrm{C}$ for LSRN isomerization. The yield of naphtha increases over $90 \mathrm{wt} \%$ and with RON of about $95-98$ using Isomalk- $4^{\mathrm{SM}}$. In addition, refiners can comprehend the maximum naphtha molecules, and reduce cracking and formation of benzene. The $\mathrm{C}_{7}{ }^{+}$stream is directed to Isomalk- $4^{\mathrm{SM}}$ unit to attain the equilibrium quantity of di and trimethylbutanes, which have high-octane numbers [31]. The reformer's feedstock is controlled to reduce the precursors of benzene, cracking, and hydro dealkylation reactions, thus increasing the RON and yield of the product. The basic configuration used in GTC is once-through isomerization and once-through with prefeed deisopentanizer. Recycling of low-octane pentanes and hexanes and full recycling of all non-branched paraffin and pre-feed deisopentanizer.

\section{Axen technology}

Axen uses chlorinated alumina (ATIS-2L) catalyst for isomerization of LSRN. The configurations used for the isomerization are once-through, DIH, IPSORB ${ }^{\mathrm{TM}}$, and HEX$\mathrm{ORB}^{\mathrm{TM}}$. The once-through configuration is used when there are two reactors in series and paraffin do not recycle back to the reactor. Therefore, this technique requires the lowest investment. The recycling of unconverted methyl pentanes is required to achieve octane number above 83 . The addition of DIH at the downstream of the reactor is a reasonable step that increases the octane number. The DIH separates the volatile $\mathrm{C}_{5}$ molecules and DMB's as a top products, which are combined again with the fraction at the bottom to make the final product. Side stream contains methyl pentanes that are recycled back to the reactor to produce a product with higher octane number. The RON increases from 70 to $83-84$ after isomerization.

\section{Axen IPSORB $^{\mathrm{TM}}$}

In this process, the feedstock is first sent to the deisopentanizer unit, where iso pentane is removed from the feedstock. The mixture is then sent to the molecular sieve adsorption unit, where $n$-paraffin and iso-paraffin are separated, and isomerates are removed after stabilization. The off gases are removed and paraffin having lower RON are sent back to the reactor. The product has RON in the range of $88-89$. Figure 3 shows the configuration of the industrial IPSORB process [29]. The unconverted normal paraffin are removed from the product by the help of stabilizer that is followed by the adsorption system (Fig. 3). Vapors rich in iso pentane are used in desorption of the $n$-paraffin and are sent back to the DIP upstream. Separation of i-pentane from the fresh feedstock decreases the flow rate of the stream into the reactor that increases the conversion of $n$-pentane to i-pentane. As the adsorption is carried out on the molecular sieve basis with the size of about $5 \AA$, it gives high capacity for adsorption while operating under pressure swing adsorption.

\section{Axen HEXORB ${ }^{\text {TM }}$}

This process uses molecular sieve adsorption technique and deisohexanizer to separate iso hexane and methyl pentane. The RON of the product is up to 92 that can be attained with full conversion of $n$-paraffins by assimilating the HEX$\mathrm{ORB}^{\mathrm{TM}}$ process. The HEXORB process for isomerization contains a system of molecular sieve adsorption along with a downstream DIH column that separates it into isomerate and methyl pentanes. The methyl pentanes are recycled to the feed section. The bottom stream is combined with the final isomerate [29]. Table 5 shows the comparison of different isomerization configurations techniques. Figure 4 illustrates the configuration of industrial HEXORB process.

\section{UOP isomerization process}

UOP uses various techniques, including buatmar process, Penex, and Par-ISOM process. The penex process uses chlorinated $\mathrm{Pt} / \mathrm{Al}_{2} \mathrm{O}_{3}$ catalyst. It is used for the isomerization of LSRN. The buatmar process is used for the isomerization of $n$-butane, which can be further utilized in other processes [32]. The par-isom process use non-chlorinated alumina catalysts for the isomerization of LSRN. These catalysts have the ability to tolerate water and to regenerate [25].

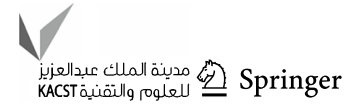


Table 5 Economics for each isomerization processing scheme using ATIS-2L chlorinated alumina catalyst

\begin{tabular}{lllll}
\hline Property & Once-through process & Recycle process with DIH & IPSORB & HEXORB \\
\hline Research octane number & $82-84[42]$ & $87-88.5[42]$ & $88-89[42]$ & $91-92[42]$ \\
$\begin{array}{l}\text { Motor octane number } \\
\begin{array}{l}\text { Annual operating cost (utilities- } \\
\text { catalyst-adsorbents) }\end{array}\end{array}$ & Base [42] [42] & $85-86.5[42]$ & $85.5-86.5[42]$ & $89-90[42]$ \\
\hline
\end{tabular}

Table 5 shows the comparison of different configuration for isomerization. This shows that maximum RON is obtained by the configuration that involves the combination of DIH and molecular sieves. However, it has high annual operating cost, and once-through process gives the lowest value of RON with least annual operating cost [29].

UOP has developed new types of catalyst for isomerization of light paraffin and offers extra flexibility for the Buatmar process and in the Penex applications. The UOP182 catalyst has the highest activity and is used in about 50 process units, since it is commercialized from 2003. UOP new catalysts used in Panex are I-84, I-122, and I-124, and are an extension of their field-proven I-82 catalyst. The key features of these catalysts are as follows:

- They are highly active catalysts and give more conversion than the previously used catalysts.

- The yield of the product exceeds $99 \%$ per unit volume.

- These catalysts have longer life.

- They are economical and have lesser reactor costs. [33]

The Panex process by UOP can bear up to 5 vol\% benzene in the feedstock stream. However, if the benzene severity in the feedstock increases than this amount then a newly advanced technology panex plus process is used. The panex plus process is well established, robust and economical for the benzene management solutions. The more active and low-density catalysts for isomerization has been established by the Axens and Akzo Nobel catalysts that are used for the production of high-octane product. In this regard, catalyst ATIS-2L gives the similar greater activity as Akzo Nobel's catalysts AT-20, but it has a relatively lower density. ATIS2L uses a lesser amount of platinum and have relatively lower density than AT-20. An experiment was performed in the pilot plant by Akzo Nobel, and results show that PIN achieved with ATIS-2L was 5-6 times more than AT-20. This indicates that ATIS-2L is $20 \%$ more active than AT-20 on a weight basis. Whenever the specification of new fuel and the cost to reload a reactor are considered, the advantages of the highly active and relatively lower density catalyst are preferred [34]. The Pilot plant tests show the excellent performance of ATIS-2L. The yield of the isomerate and octane number has been enhanced with this new catalyst. Numerous isomerization process selections are present, and all of them give benefit from the new ATIS-2L catalyst. In future, the choices to improve the octane number of current units are shown to be more cost effective.

\section{Conclusions}

This paper reviewed the isomerization process, catalysts that are used for isomerization, the main reactions that occur during the isomerization process in the reactor, the reaction mechanism, reaction conditions for the various reactions, the main contaminants that are present in the feedstock and catalyst's tolerance to various impurities that are present in the feedstock to isomerization reactor. The octane enhancement of light straight run naphtha (LSRN) is one of the significant processes in today oil refineries due to limitations of benzene, aromatics, and olefin content in gasoline. Therefore, the process of isomerization is becoming important in oil refineries as it produces compounds with fewer alkenes and aromatics. The isomerization process is classified on the basis of catalyst, configuration and feedstock. This review will benefit the oil refineries to use the suitable technology for their process.

\section{Compliance with ethical standards}

Conflict of interest On behalf of all authors, the corresponding author states that there is no conflict of interest.

Open Access This article is distributed under the terms of the Creative Commons Attribution 4.0 International License (http://creativeco mmons.org/licenses/by/4.0/), which permits unrestricted use, distribution, and reproduction in any medium, provided you give appropriate credit to the original author(s) and the source, provide a link to the Creative Commons license, and indicate if changes were made.

\section{References}

1. Hanif MA, Nisar S, Rashid U (2017) Supported solid and heteropoly acid catalysts for production of biodiesel. Catal Rev 59(2):165-188

2. Ducreux O, Jolimaitre E (2004) Process combining hydroisomerisation and separation using a zeolitic adsorbent with a mixed 
structure for the production of high octane number gasolines, Patent 6,809, 228

3. de Barros SDT, Senra JD, Lachter ER, Malta LFB (2016) Metal-catalyzed cross coupling reactions with supported nanoparticles: recent developments and future directions. Catal Rev 58(4):439-496

4. Gheit AKA, Ghoneim SA (2008) Catalysis in the petroleum naphtha catalytic reforming process. J Rec Pat Chem Eng 1:113-125

5. Zhao X, Wei L, Cheng S, Julson J (2017) Review of heterogeneous catalysts for catalytically upgrading vegetable oils into hydrocarbon biofuels. Catalysts 7(3):83

6. Sanchez LM, Thomas HJ, Climent MJ, Romanelli GP, Iborra S (2016) Heteropolycompounds as catalysts for biomass product transformations. C Rev 497-586

7. Dildari H (2005) Suitable catalyst for hydroisomerization of longchain normal paraffin. Appl Catal A 293:1-10

8. Meyers RA (1986) Handbook of petroleum refining processes. McGraw-Hill, New York, Chapter 5.2

9. Meyers RA (1986) Handbook of petroleum refining processes. McGraw-Hill, New York, Chapter 5.1

10. Eswaramoorthi I, Lingappan N (2003) Hydroisomerization of $n$-hexane over bimetallic silico alumino phosphate based molecular sieves. Appl Catal A 245:119-135

11. Low CD, Gembicki VA, Haizmann RS (1991) Isomerization of benzene-containing feedstocks, Patent-5003118 A

12. Chuzlov VA, Molotov KV (2016) Development of computer modelling system as a tool for light naphtha isomerization improvement. Petrol Coal 58:47-55

13. Rossi KJD, Dovedytis DJ, Esteves DJ, Harandi MN, Huss A (1994) Combined paraffin isomerization/ring opening process for $\mathrm{C}_{5}{ }^{+}$naphtha, Patent-5,334,792

14. Fersing M, Nascimento $P$ (2002) Method for the isomerization of gasoline with a high benzene content, Patent-6,416,657

15. Modica FS, Naperville (1993) Process for the catalytic isomerization of Light naphtha, Patent-5, 233, 121

16. Graeme S, Laan MVD (2003) Butane and light naphtha isomerization. Pet Technol Q 8:47-49

17. Funez A, Lucas AD, Sanchez P (2008) Hydroisomerization in liquid phase of a refinery naphtha stream over Pt-Ni/H-beta zeolite catalysts. Chem Eng J 136:267-275

18. Miyaji A, Okuhara T (2003) Skeletal isomerization of $n$-heptane and hydroisomerization of benzene over bifunctional heteropoly Compounds. Catal Today 81:43-49

19. Fahim M, Al-Sahhaf T, Elkilani A (2010) Fundamentals of petroleum refining. Elsevier, Oxford, p 120

20. He M, Zhang J, Liu R, Sun X, Chen B (2017) The distribution and strength of brönsted acid sites on the multi-aluminum model of FER zeolite: a theoretical study. Catalysts 7(1):11

21. Graeme S, Ross J. Advanced solutions for paraffin isomerization. NPRA Annual Meeting, San Antonio, TX, March 21-23
22. Graeme WS, Laan MNTVD () Development and commercialization of ATIS-2L, a high activity, low cost paraffin isomerization Catalyst, Akzo Nobel Catalysts Symposium, Noordwijk, the Netherlands, June 10-13

23. Argyle MD, Bartholomew CH (2015) Heterogeneous catalyst deactivation and regeneration: a review. Catalysts 5(1):145-269

24. Bartholomew CH, Argyle MD (2015) Advances in catalyst deactivation and regeneration. Catalysts 5(2):949-954

25. Ivanov AV, Vasina TV, Nissenbaum VD, Kustov LM, Timofeeva MN, Houzvicka JI (2004) Isomerization of $n$-hexane on the Ptpromoted Keggin and Dawson tungstophosphoric hetero poly acids supported on zirconia. Appl Catal A 259:65-72

26. Sukkar KA, Abdul-Raheem HM, Juber AT, Jumaley JS (2007) Study of catalysts deactivation in isomerization process to produce high octane gasoline. IJCPE 8:43-48

27. Radhi MA, Al-Mutawalli FS, Al-Sammarie EA (1989) Isomerization of $n$-hexane and $n$-pentane mixture on Pt-alumina catalyst. Fuel Sci Tech Int 7:143-163

28. Meyers RA (1986) Handbook of petroleum refining processes. McGraw-Hill, New York, Chapter 5.5

29. Speight JG, Ozum B (2002) Petroleum refining processes. Marcel Dekker, New York

30. Meyers RA (1986) Handbook of petroleum refining processes. McGraw-Hill, New York, Chapter 9

31. Meyers RA (1986) Handbook of petroleum refining processes. McGraw-Hill, New York, Chapter 5.4

32. Isomerization. https://www.uop.com/products/catalysts/isomerizat ion/

33. Graeme S, Ross J () Advanced solutions for paraffin isomerization. In: Proceedings of the NPRA Annual Meeting, San Antonio, TX, March 21-23

34. Al-Sahhaf TA, Elkilani A, Fahim MA (2010) Fundamentals of petroleum refining, 5th ed. Elsevier, Netherlands, Chapter 5.2.4.4

35. Al-Sahhaf TA, Elkilani A, Fahim MA (2010) Fundamentals of petroleum refining, 5th ed. Elsevier, Netherlands, Chapter 5.2.4.5

36. Al-Sahhaf TA, Elkilani A, Fahim MA (2010) Fundamentals of petroleum refining, 5th ed. Elsevier, Netherlands, Chapter 5.2.4.4

37. Butane isomerization Isomalk-3. http://nefthim.com/developmen ts/butane-isomerization-isomalk-3/

38. $\mathrm{C}_{7}$-fraction Isomerization Isomalk-4. http://nefthim.com/devel opments/Light-gasoline-fractions-isomerization/

39. Isomerization high octane $\mathrm{C}_{5} / \mathrm{C}_{6}$ cuts via isomerization processes. http://www.digitalrefining.com/data/literature/file/1263042721 .pdf

Publisher's note Springer Nature remains neutral with regard to jurisdictional claims in published maps and institutional affiliations. 